\title{
The human premaxilla and Goethe
}

\author{
Kun Hwang, Seon Mi Yun \\ Department of Plastic Surgery, Inha University School of Medicine, Incheon, Korea
}

It is safe to say that most plastic surgeons are familiar with the growth pattern of the premaxilla in bilateral cleft lip and palate patients, in whom in utero growth of the premaxilla is excessive and directed more horizontally, resulting in a protrusive premaxilla at birth [1]. Despite the common usage of the name of this bone, the origin of its nomenclature is not widely known to many plastic surgeons. I have carried out a review of publications about the premaxilla.

When Galen (131-201) was active, the premaxilla had already been observed in animals. Coiter (1573) was the first anatomist to describe this medial part of the upper jaw as a separate bone in the vertebrate skull. He also illustrated the incisive suture (sutura incisiva) in humans [2].

In the 18th century, Petrus Camper from Holland stated that a vitally important anatomical difference between humans and animals was the missing intermaxillary bone (premaxilla) in man, with this being the distinguishing feature between humans and monkeys. Contradicting this theory, Goethe (1749-1832) found the intermaxillary bone in the human skull in 1784 [3]. Goethe hoped to present this discovery through his friend Johann Merck, who was in contact with Camper and could serve as an intermediary. However, Merck delayed forwarding the manuscript and also did not forward Camper's eventual replies. Thirty-six years later, in 1820, Goethe submitted his hypothesis, but it was rejected by the leading anatomists of the time.

Last year I visited Leipzig for research collaboration. In Leipzig, I saw the statue of Goethe (Goethedenkmal), which reminded me of the name of a pub (Auerbachs Keller) that ap-

Correspondence: Kun Hwang

Department of Plastic Surgery, Inha University School of Medicine, 27 Inhang-ro, Jung-gu, Incheon 22332, Korea

E-mail: jokerhg@inha.ac.kr

Received August 16, 2019 / Revised August 17, 2019 / Accepted August 18, 2019 pears in his Faust, which is set in that city. The Korean researcher accompanying me led me to the tavern and said that Goethe (1749-1832) was a regular at Auerbachs Keller as a university student from 1765 to 1768 .

I saw the statues of Faust and Mephistopheles at the gate of that tavern. I also viewed a wall painting depicting the last scene of Faust. In the first edition of Faust, I observed that the midface and upper lips of Mephistopheles and Martha were retracted and the lower lip protruded like that of a cleft palate patient (Fig. 1).
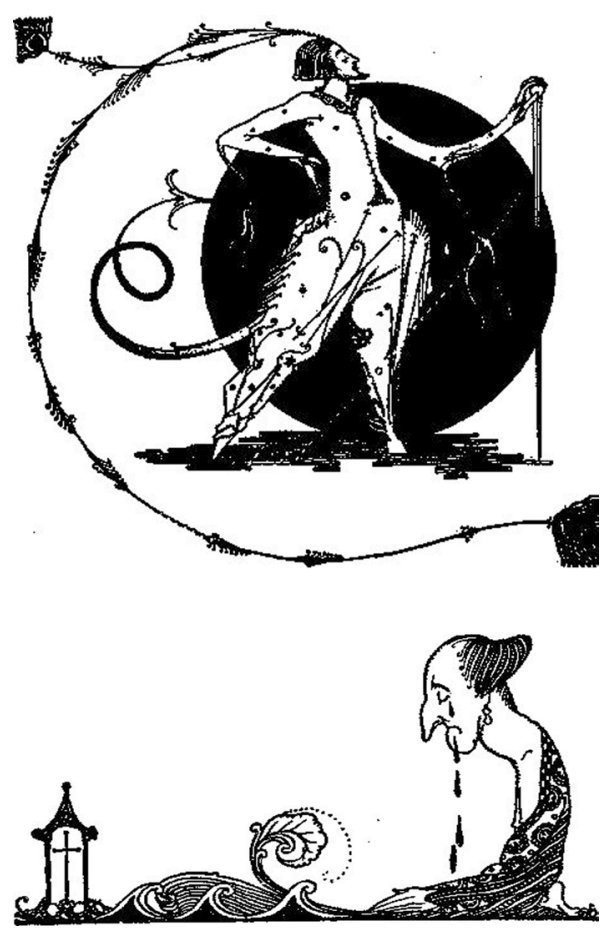

Fig. 1. Mephistopheles (upper) and Martha (lower) in the first edition of Faust (1808). 
It is therefore possible that Goethe's discovery of the premaxilla in humans, which he did not succeed in publishing, was reflected in the painting of Mephistopheles and Martha, who were portrayed with the retracted maxilla that is seen in cleft palate patients and elderly people who are losing their maxillary teeth.

\section{NOTES}

\section{Conflict of interest}

No potential conflict of interest relevant to this article was reported.
ORCID

Kun Hwang https://orcid.org/0000-0002-1994-2538

Seon Mi Yun https://orcid.org/0000-0002-7099-4245

\section{REFERENCES}

1. Vargervik K. Growth characteristics of the premaxilla and orthodontic treatment principles in bilateral cleft lip and palate. Cleft Palate J 1983;20:289-302.

2. Barteczko K, Jacob M. A re-evaluation of the premaxillary bone in humans. Anat Embryol (Berl) 2004;207:417-37.

3. Hellmich S, Hellmich J. The intermaxillary bone and Goethe's Mephistopheles. Laryngol Rhinol Otol (Stuttg) 1982;61:552-6. 